\title{
Antarctic precipitation and its contribution to the global sea-level budget
}

\author{
David H. Bromwich, ${ }^{1,2}$ Richard I. Cullather, ${ }^{1}$ Michael L. Van Woert ${ }^{3}$ \\ ${ }^{1}$ Polar Meteorology Group, Byrd Polar Research Center, The Ohio State University, Columbus, OH 43210-1002, U.S.A. \\ ${ }^{2}$ Atmospheric Sciences Program, The Ohio State University, Columbus, OH 43210-1002, U.S.A. \\ ${ }^{3}$ Office of Research and Applications, NOAA National Environmental Satellite, Data, and Information Service, Washington, \\ DC 20233-9910, U.S.A.
}

\begin{abstract}
Antarctic precipitation estimations derived from several new sources are examined in comparison to results found previously. The availability of analyzed atmospheric datasets has been a significant and beneficial tool for atmospheric and climate research for a broad range of research interests. This is particularly true for the polar regions, where the observational arrays are sparsely distributed. In high southern latitudes, a comprehensive assimilation of all available observations, including satellite data, is necessary for an accurate depiction of the atmospheric circulation. Recent studies have found the operational analyses of the European Centre for Medium-range Weather Forecasts to be superior to those of other weather-forecasting centers in depicting the large-scale atmospheric circulation patterns over Antarctica. "Re-analysis" programs at major weather-forecasting centers have produced atmospheric numerical analyses using a "frozen" data-assimilation system. These projects have also derived precipitation and evaporation fields using an ensemble of short-term forecasts. From these new sources, Antarctic $P-E$ (precipitation minus evaporation/sublimation) is compared and evaluated against the long-term glaciological synthesis, as well as results from previous studies. The comparisons indicate significant regional disagreements exist between $P-E$ from the re-analysis forecasts and the glaciological data. For the ensemble forecasting method, the continental-average evaporation is the largest area of uncertainty and differs by an order of magnitude between the re-analysis datasets. This finding supports the use of the atmospheric moisture budget for determining $P-E$ collectively in atmospheric diagnostic studies for Antarctica.
\end{abstract}

\section{INTRODUCTION}

Global sea level is an important variable with clear relevance to climate-change study (Warrick and others, 1996). Recent satellite programs, including ERS-1 and TOPEX/ Poseidon, have examined global sea-level temporal variability over limited periods of time (Nerem, 1997). An accurate appraisal of future eustatic change requires a detailed understanding of the various sea-level budget components. One of the largest areas of uncertainty is the contribution of the Antarctic ice sheet. Annual accumulation over the continent has previously been estimated to be approximately $5 \mathrm{mma}^{-1}$ in equivalent global sea-level (ESL) decrease (Fortuin and Oerlemans, 1990). This quantity is generally restored to the sea-level budget through iceberg calving and basal melting of ice shelves. Variability in atmospheric circulation can alter ice-sheet precipitation over short time-scales, while the ice-sheet response occurs over much longer time-scales (Fortuin and Oerlemans, 1990). Investigations using global climate models (Ohmura and others, 1996; Thompson and Pollard, 1997) suggest that Greenland and Antarctic surface mass balances make opposite contributions to the present global sea-level rise, with the negative contribution of Antarctica dominating. Observational estimates of recent Antarctic precipitation variability, however, are encumbered by a variety of factors (Bromwich, 1988). Biases associated with wind-induced tur- bulence and the introduction of blowing snow create tremendous difficulties in using snow-gauge measurements. Glaciological measurements of accumulation are generally considered straightforward, but the available observations lack the uniform spatial and temporal resolution needed to examine the continental area. These deficiencies in surfacebased measurements have led to the examination of atmospheric techniques, including assimilated datasets.

Atmospheric numerical analyses are routinely produced by operational weather-forecasting centers for the purpose of initializing short- and medium-range weather-forecasting models. The analyses incorporate all meteorological data that are available to the forecasting center, including satellite data. The archiving of these analyzed fields has produced an important tool for use in meteorological and climate study (e.g. Trenberth and Olson, 1988; Trenberth, 1992). Recent studies (Bromwich and others, 1995; Cullather and others, 1997) have shown the analyses produced by the European Centre for Medium-range Weather Forecasts (ECMWF) are superior to other analyses in depicting the large-scale circulation features and moisture budget of high southern latitudes. The atmospheric moisture budget study of Bromwich and others (1995) and other recent studies (Howarth, 1986; Masuda, 1990; Yamazaki, 1992, 1994; Budd and others, 1995) have demonstrated the viability of this method. A significant difficulty with the use of operational analyses for climate study is the fact that the analyses are 
produced primarily to initialize short-term forecast models. Changes are frequently made to the data-assimilation system for the improvement of the forecast model. This creates the problem of discerning spurious changes to the analysis system from real climate variability in an extended time series. In an effort to address this problem, "re-analyses" have been produced using a "frozen" data-assimilation system. In these data, either variability is a real signal of the natural atmosphere or it results from changes in the data network. The expanded datasets from the re-analyses include fields from short-term forecasts initialized using the re-analyzed initial fields.

In this paper we examine the results obtained by Cullather and others (1998) using the moisture budget of the operational ECMWF analyses, in comparison to the recently available datasets of the ECMWF and U.S. National Centers for Environmental Prediction/National Center for Atmospheric Research (NCEP/NCAR) reanalysis projects. Section 2 presents an overview of the datasets considered in this study, as well as the moisture-budget method employed on the ECMWF operational analyses. In section 3, an assessment is made of the spatial depictions in comparison to the long-term glaciological synthesis. Section 4 presents a comparison of the annual cycles and interannual variability produced by each of these methods. These results are examined in the context of the Antarctic icesheet contribution to the global sea-level budget. Finally, section 5 presents an overview of issues related to Antarctic precipitation variability.

\section{DATASETS AND THE ATMOSPHERIC MOIST- URE BUDGET}

Several different types of precipitation data are available for polar ice sheets. These different variables are related via the surface budget using (Bromwich, 1988):

$$
\langle\bar{B}\rangle=\langle\bar{P}\rangle-\langle\bar{E}\rangle-\langle\bar{D}\rangle-\langle\bar{M}\rangle
$$

where angled brackets represent an areal average and the overbar represents a time average, $B$ is accumulation, $P$ is precipitation, $E$ is the net of sublimation minus deposition of hoar-frost, $D$ is the divergence of snowdrift transport and $M$ is the divergence of meltwater runoff. In estimating ice-sheet mass balance, the areal accumulation rate is balanced against iceberg calving and basal melting at the bottom of ice shelves. A review of these terms is given by Jacobs and others (1992). It should be noted that Equation (1) is somewhat idealistic in partitioning the various contributions. For example, sublimation from blowing snow may be significant. Notwithstanding, the dominant term in Equation (l) is precipitation, and, to a first order, the spatial distributions of $B, P$ and $P-E$ have been thought to be comparable (Bromwich, 1988), although evaporation/sublimation can be large (e.g. Stearns and Weidner, 1993).

The operational ECMWFanalyses used in this study are from the Tropical Oceans Global Atmosphere (TOGA) Archive II, a twice-daily global $2.5^{\circ} \times 2.5^{\circ}$ dataset reported at near-surface and 14 standard pressure levels. After 1991, the dataset includes a 15 th level at $925 \mathrm{hPa}$, which is omitted here for temporal continuity. The dataset is described and evaluated by Trenberth (1992). In addition to the moisturebudget study of Bromwich and others (1995), Cullather and others (1997) have evaluated the standard ECMWF and NCEP variables over Antarctica using available rawin- sonde, automatic weather station, ship, and synthesized long-term observations. The ECMWF analyses were generally found to be superior, and to depict reasonably the broad-scale atmospheric circulation.

From these operational ECMWF analyses, the moisture budget was computed for the years 1985-93 using the method outlined in Cullather and others (1998). A derivation of the atmospheric moisture budget is given by Peixoto and Oort (1992) from first principles. The budget may be expressed as:

$$
\langle\bar{P}-\bar{E}\rangle=-\left\langle\overline{\frac{\partial W}{\partial t}}\right\rangle-\frac{1}{A} \oint\left\{\overline{\int_{P_{\text {top }}}^{P_{\text {sfc }}} \frac{q \mathbf{V}}{g} \mathrm{~d} p}\right\} \mathbf{n} \mathrm{d} l,
$$

where $A$ is the area of interest, $W$ is precipitable water, $P_{\text {sfc }}$ is surface pressure, $q$ is specific humidity, $\mathbf{V}$ is the horizontal wind vector and $\mathbf{n}$ is the outward-pointing normal vector of the area perimeter. The variable $P_{\text {top }}$ is the highest level of the atmosphere, which is not zero in the analyses. In the operational ECMWF analyses, horizontal wind data extend to $10 \mathrm{hPa}$, while atmospheric moisture is considered negligible above $300 \mathrm{hPa}$. Equation (2) is written so that the residual is expressed as $P-E$ for comparison with glaciological accumulation. The first term on the righthand side is the time derivative of precipitable water, and is referred to as the storage term. Four adjacent gridpoints are used to define an area and boundary. The units in Equation (2) are kg $\mathrm{m}^{-2} \mathrm{~s}^{-1}$, which is equal to the rate of $\mathrm{mm} \mathrm{s}^{-1}$ of water-equivalent precipitation.

A comprehensive review of the NCEP/NCAR reanalysis project is given by Kalnay and others (1996). The system utilizes a quality-controlled data-assimilation system and a global spectral numerical weather-prediction model with T62 horizontal resolution (approximately $1.9^{\circ} \times 1.9^{\circ}$ ) and 28 vertical levels. Some of the important considerations for examining the NCEP/NCAR re-analysis in high southern latitudes are outlined in Cullather and others (1998). These include the misincorporation of manually derived

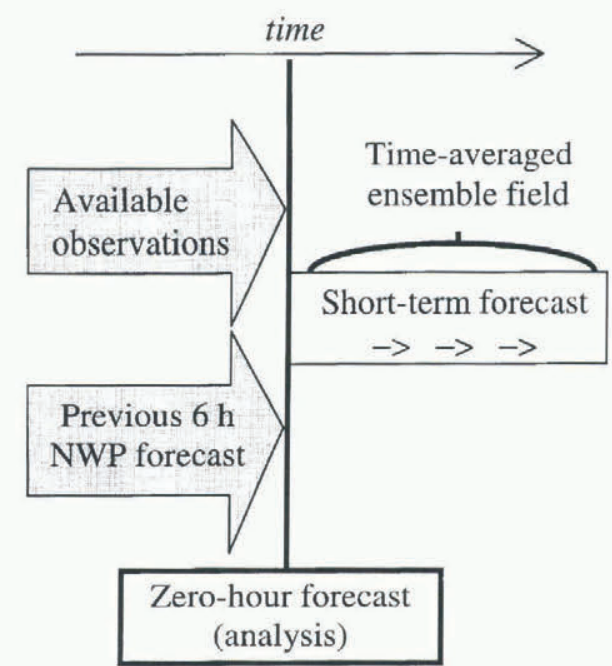

Fig. 1. Diagram indicating evolution of various weather-forecasting-center products. Numerical analyses, from which the atmospheric moisture budget may be computed, are produced at the zero forecast hour. Precipitation and evaporation fields are obtained from an average over some period of the shortterm forecast. The procedure is repeated twice or four times daily to produce an ensemble of analyses and short-term forecasts. 

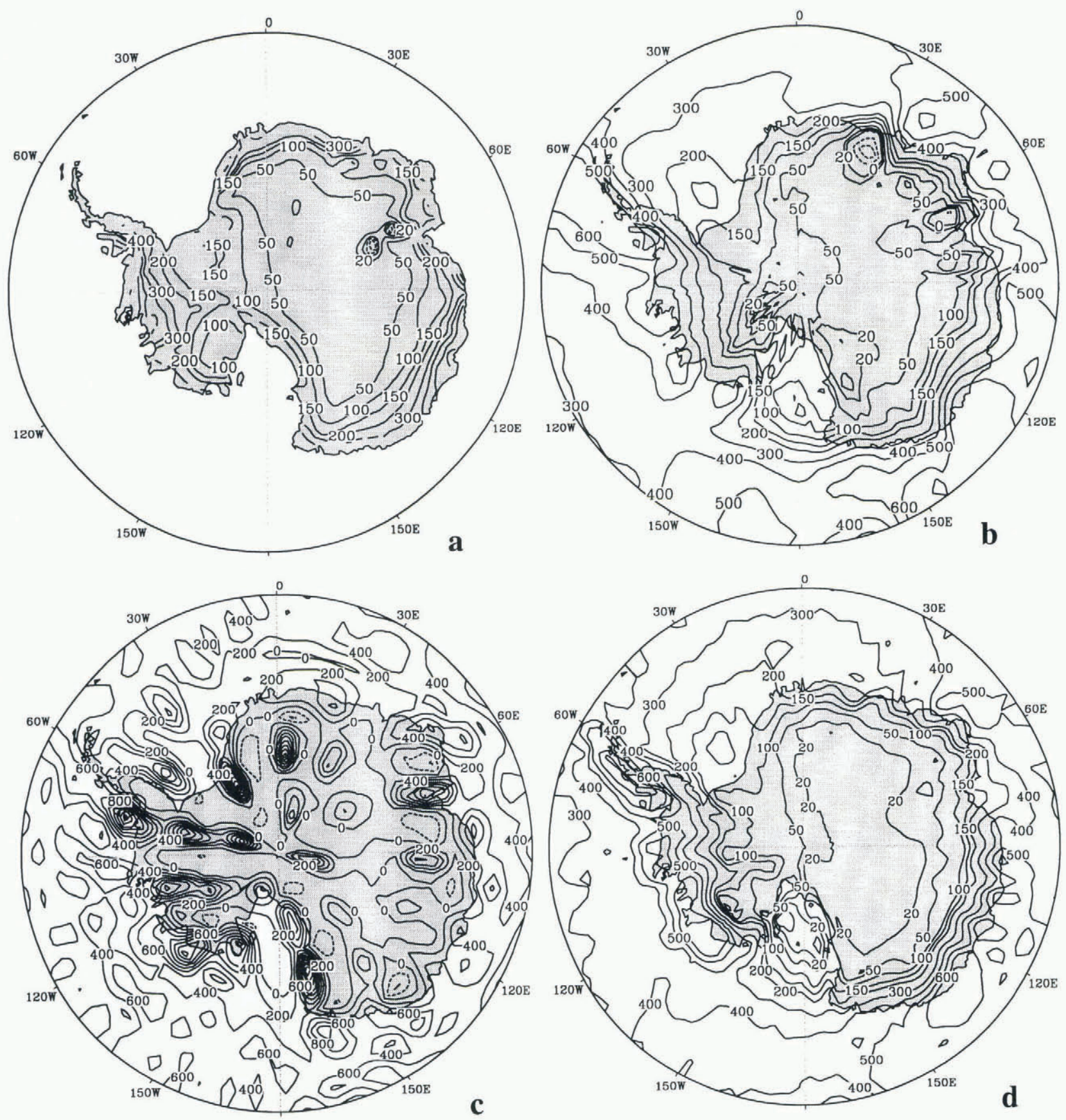

Fig. 2. (a) Digitized accumulation synthesis from Giovinetto and Bentley (1985), plotted in units of mm w.e. $a^{-1}$. Spatial distribution of $P-E$ derived from $(b)$ the atmospheric moisture budget of ECMWF operational analyses, $(c)$ ensemble forecasts of the $\mathcal{N C E P} / \mathcal{N} C A R$ reanalysis, and (d) ensemble forecasts of the ECMWFre-analysis, averaged for the years 1985-93, plotted in units of mm w.e. $a^{-1}$. Contour intervals selected by Giovinetto and Bentley are used in $(a),(b)$ and $(d)$; a constant interval of $200 \mathrm{~mm} \mathrm{a}^{-1}$ is used in (c) for legibility.

sea-level pressure observations over the Southern Hemisphere during the assimilation process, and a spurious spectral distortion pattern in polar moisture fields. These two errors suggest considerable caution in evaluating results over the Antarctic. The ECMWF re-analysis project (ERA) also utilizes a refined data-assimilation system and a T106 forecast model with 31 vertical levels (Gibson and others, 1996, 1997).

Figure 1 is an attempt to illustrate the differences between (1) numerical analyses, from which the moisture budget may be computed, and (2) short-term forecasts, from which the average forecast precipitation field is produced. Numerical analyses are produced from the assimilation of available meteorological observations, as well as the previous 6 hour numerical weather prediction forecast, referred to as the first guess. These two sources of data are then passed through a quality-control procedure to produce the zero-hour global analysis. From the zero-hour analysis, the forecast model is then run and average precipitation and evaporation rates are computed for some part of the forecast run. The NCEP/NCAR re-analyses utilize the 0-6 hour forecast period, while the ERA uses the 12-24 hour forecast period to avoid "spin-up" in the early hours of the forecast. The procedure shown in Figure 1 is then repeated to produce numerical analyses four times daily. For a 30 day month, an ensemble of 60 short-term forecasts is used to produce the monthly-averaged precipitation and evaporation fields from the ERA. 


\section{SPATIAL DISTRIBUTIONS}

The long-term synthesis of glaciological observations is an important benchmark for comparison with new datasets. The most recent of these is the synthesis of Giovinetto and Bentley (1985), which has been used for validation in numerous studies (e.g. Tzeng and others, 1994; Connolley and King, 1996; Ohmura and others, 1996). Two recent studies have demonstrated local discrepancies in the climatology in the vicinity of the Antarctic Peninsula (Frolich, 1992) and Lambert Glacier (Higham and Craven, 1997). These studies suggest the need for a revised accumulation distribution for the continent, but also illustrate the problem faced when synthesizing a long-term variable for regions where values are susceptible to interannual variability. The Giovinetto and Bentley climatology is the best synthesis of glaciological data currently available, however. Giovinetto and Bentley (1985) indicated an uncertainty of $\pm 10 \%$ in their accumulation estimate for Antarctica. This climatology has recently been produced in a digital version by its authors, which is shown in Figure 2a. This digital version contains data only for the grounded ice-sheet areas, which is sufficient for this study of the eustatic impact. The field contains values at a $1^{\circ} \times 1^{\circ}$ latitude/longitude resolution. The areal average of this field where values are available is $151 \mathrm{~mm} \mathrm{a}^{-1}$.

Figure $2 \mathrm{~b}$ shows the spatial distribution of $P-E$ derived from the atmospheric moisture budget using ECMWF operational analyses, averaged for the years 1985-93. The figure is qualitatively similar to the Giovinetto and Bentley climatology in showing essentially desert-like conditions over a large area of the East Antarctic interior surrounded by a large spatial gradient along the coast. Larger values are present in West Antarctica, with the continent's largest values occurring along the western side of the Antarctic Peninsula. The average of these data for the identical region used in the Giovinetto and Bentley climatology is $137 \mathrm{~mm}$ $\mathrm{a}^{-1}$. Figure 3 presents the difference of the ECMWF moisture budget $P-E$ minus the Giovinetto and Bentley accumulation. Large regional differences are particularly noticeable in coastal regions; there are several areas where features are transposed, such as to the west and east of $30^{\circ} \mathrm{E}$ in Dronning Maud Land. A particularly interesting feature occurs near Porpoise Bay $\left(\sim 125^{\circ} \mathrm{E}\right)$ where the moisture budget exceeds accumulation by $>250 \mathrm{~mm} \mathrm{a}^{-1}$. Near the Ross Ice Shelf and West Antarctica, several regional features in the accumulation data (Fig. 2a) appear to be below the resolution available to the moisture-budget method. These include the maxima along the Transantarctic Mountains, and the minima associated with subsidence along the eastern edge of the Ross Ice Shelf and into West Antarctica, although interannual variability has been found to be large in this region (Cullather and others, 1996).

The distorted spatial pattern for NCEP/NCAR reanalysis $P$ has been reported by Cullather and others (1996, 1998). Distortions in the $P-E$ field, shown in Figure $2 c$, are qualitatively similar. The field is characterized by a spectral distortion pattern resulting in a variety of maxima, or bull's-eyes, scattered throughout the interior of Antarctica and into lower latitudes but mostly confined to $70^{\circ} \mathrm{S}-$ South Pole. The magnitude of these spatial oscillations is on the order of $400 \mathrm{~mm} \mathrm{a}^{-1}$ for the $1985-93$ mean field. A similar problem has also been found in the Arctic (Serreze and Maslanik, 1997). This is combined with a known dataassimilation problem for the inclusion of manually derived

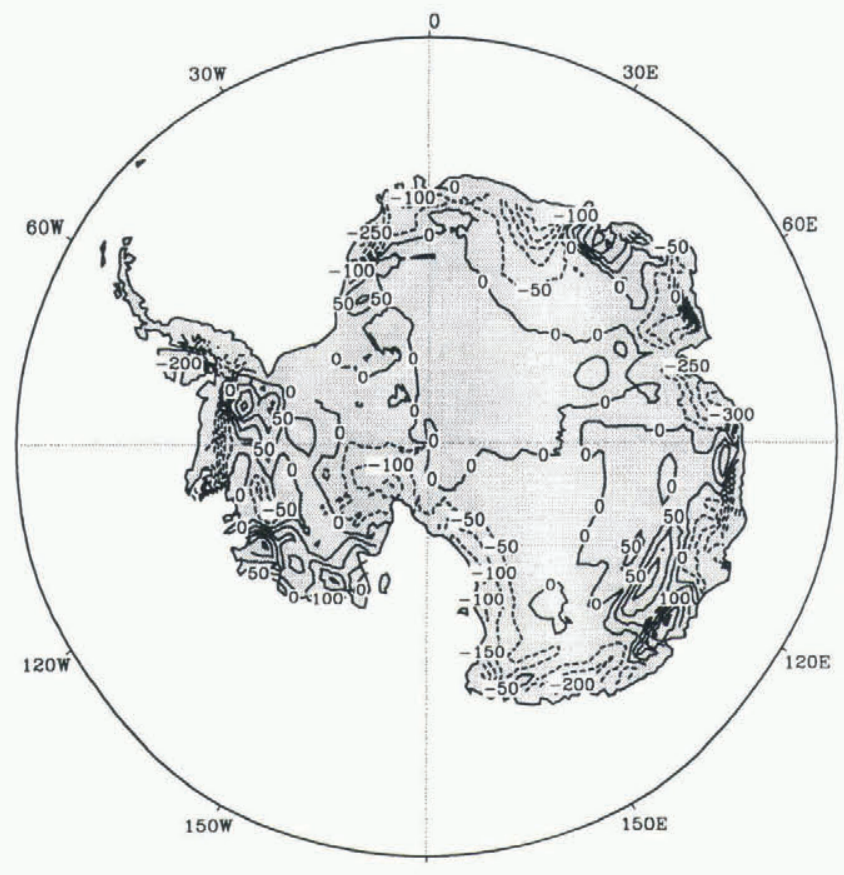

Fig. 3. Difference of $P-E$ derived from the atmospheric
moisture budget using ECMWF operational analyses minus
Giovinetto and Bentley (1985) digitized accumulation. The
contour intervals are every $50 \mathrm{~mm} \mathrm{a}^{-1}$.

sea-level pressure observations over the Southern Hemisphere, which are substantial caveats for examining timeseries results.

Figure 2d shows the corresponding $P-E$ field from ensemble forecasts of the ERA. Superficially, the ERA-ensemble-forecasted $P-E$ spatial distribution appears to be superior to the other methods discussed here in comparison with Giovinetto and Bentley (1985). This is particularly true of the contour-parallel distribution for most of the continent, and the strong gradient along the East Antarctic coastline. A difference plot of this field with the Giovinetto and Bentley climatology, not shown, shows similar regional differences to those found using the moisture-budget method. This is particularly true of the Porpoise Bay region, along the Transantarctic Mountains and in West Antarctica. An exception to this is over the interior plateau, where the values are generally much less than for the accumulation field. ERA values for the highest part of the plateau are lower than those produced by the Giovinetto and Bentley synthesis by about $25 \mathrm{~mm} \mathrm{a}^{-1}$. This may be seen in Figure $2 \mathrm{~d}$ by the large area covered by the $20 \mathrm{~mm} \mathrm{a}^{-1}$ contour, which is absent from the Giovinetto and Bentley (1985) plot (Fig. 2a).

The areal averages of $P-E$ for the grounded ice sheet are $137 \mathrm{~mm} \mathrm{a}^{-1}$ for the moisture budget from ECMWF operational analyses, $139 \mathrm{~mm} \mathrm{a}^{-1}$ for the ERA ensemble forecasts, and $161 \mathrm{~mm} \mathrm{a}^{-1}$ for the NCEP/NCAR re-analysis. All three averages are within $11 \%$ of the glaciological synthesis value of $151 \mathrm{~mm} \mathrm{a}^{-1}$ for the grounded ice sheet. It should again be noted that contemporary data are only available from the atmospheric methods; an understanding of the discrepancies with glaciological data beyond what is presented here would require concurrent data from all methods. The comparison illustrates this limitation associated with using the long-term glaciological synthesis.

The agreement found in the average annual $P-E$ value for Antarctica among the various methods is indica- 
Table 1. Comparison of $P-E$ and accumulation estimates for the Antarctic ice sheet from recent studies

\begin{tabular}{|c|c|c|c|}
\hline Study & Estimate & Method & $\begin{array}{c}\text { Value } \\
\mathrm{mm} \mathrm{a}^{-1}\end{array}$ \\
\hline Giovinetto and Bentley (1985) & Accumulation & Estimate from digitized climatology based on synthesis of glaciological data & $143 \pm 14$ \\
\hline Bromwich (1990) & $P-E$ & Integration of Giovinetto and Bentley (1985) and atmospheric studies & $151-156$ \\
\hline This study & $P-E$ & Atmospheric moisture budget from ECMWF operational analyses, 1985-93 & $149 \pm 14^{*}$ \\
\hline Yamazaki (1992) & $P-E$ & Atmospheric moisture budget from NCEP operational analyses, $1986-90$ & $135 \pm 18 *$ \\
\hline Budd and others (1995) & $P-E$ & $\begin{array}{l}\text { Atmospheric moisture budget from Australian global atmospheric assimilation and } \\
\text { prediction analyses, 1989-92 }\end{array}$ & 157 \\
\hline This study & $P-E$ & ERA ensemble precipitation and evaporation/sublimation forecasts, $1985-93$ & $157 \pm 11^{*}$ \\
\hline This study & $P-E$ & $\begin{array}{l}\text { NCEP/NCAR re-analysis ensemble precipitation and evaporation/sublimation } \\
\text { forecasts, 1985-93 }\end{array}$ & $195 \pm 12^{*}$ \\
\hline Genthon and Braun (1995) & $P-E$ & $\begin{array}{l}\text { ECMWF operational ensemble precipitation and evaporation/sublimation forecasts, } \\
1985-91\end{array}$ & 139 \\
\hline
\end{tabular}

*Standard deviation of annual values.

tive of the general agreement found among other studies (Cullather and others, 1998). A comparison of results presented here with recent studies is shown in Table 1 . The estimates are computed for an area that includes the grounded Antarctic ice sheet plus the large ice shelves. This area definition has been used as a basis for comparison in previous studies. The combined $P-E$ estimate for the studies shown is $155 \mathrm{~mm} \mathrm{a}^{-1}$ with a standard deviation of $13 \%$. Removing the outlying NCEP/NCAR re-analysis estimate reduces the average to $148 \mathrm{~mm} \mathrm{a}^{-1}$ with a standard deviation of $6 \%$.

\section{TEMPORAL VARIABILITY}

The distribution over the annual cycle for the grounded ice sheet, shown in Figure 4a, varies considerably among the datasets. There is agreement that winter values are larger than those for summer. A seasonality index computed from the ratio of winter (June-August) to summer (DecemberFebruary) values finds three different amplitudes, ranging from a small annual cycle for the ERA (1.4) to a larger cycle for the NCEP/NCAR re-analysis (2.4), with the ECMWF moisture budget almost exactly in between (1.9). The discrepancies among the atmospheric methods result from estimates of evaporation/sublimation required for the ensemble model methods. This is further discussed in section 5 .

Figure $4 \mathrm{~b}$ presents the annual values for Antarctica in units of $\mathrm{mm}$ ESL. Over the 9 year time period, the maximum range for the methods estimating $P-E$ is $1.1-1.5 \mathrm{~mm}$ ESL $^{-1}$. Both the moisture budget computed from ECMWF operational analyses and the ERA ensemble forecasts show an average value of $4.8 \mathrm{~mm} \mathrm{ESL} \mathrm{a}^{-1}$, while the NCEP/ NCAR ensemble forecasts show a value of $5.6 \mathrm{~mm} \mathrm{ESL} \mathrm{a}^{-1}$. The ECMWF moisture-budget method shows a significant upward trend of $0.12 \mathrm{~mm} \mathrm{ESL} \mathrm{a}^{-1}$ with a standard error of $0.045 \mathrm{mmESLa}^{-1}$. The NCEP/NCAR re-analysis also shows a significant upward trend, with a rate of $0.07 \mathrm{~mm} \mathrm{E}$ $\mathrm{SL} \mathrm{a}{ }^{-1}$ with a standard error of $0.05 \mathrm{~mm} \mathrm{ESL} \mathrm{a}^{-1}$. The ERA also shows a positive trend of $0.04 \mathrm{~mm} \mathrm{ESL} \mathrm{a}^{-1}$, but the slope is not significant in comparison to the variability. Nevertheless, a long-term increase is in agreement with available glaciological observations (e.g. Morgan and others, 1991; Bromwich and Robasky, 1993; Mosley-Thompson and others, 1995).
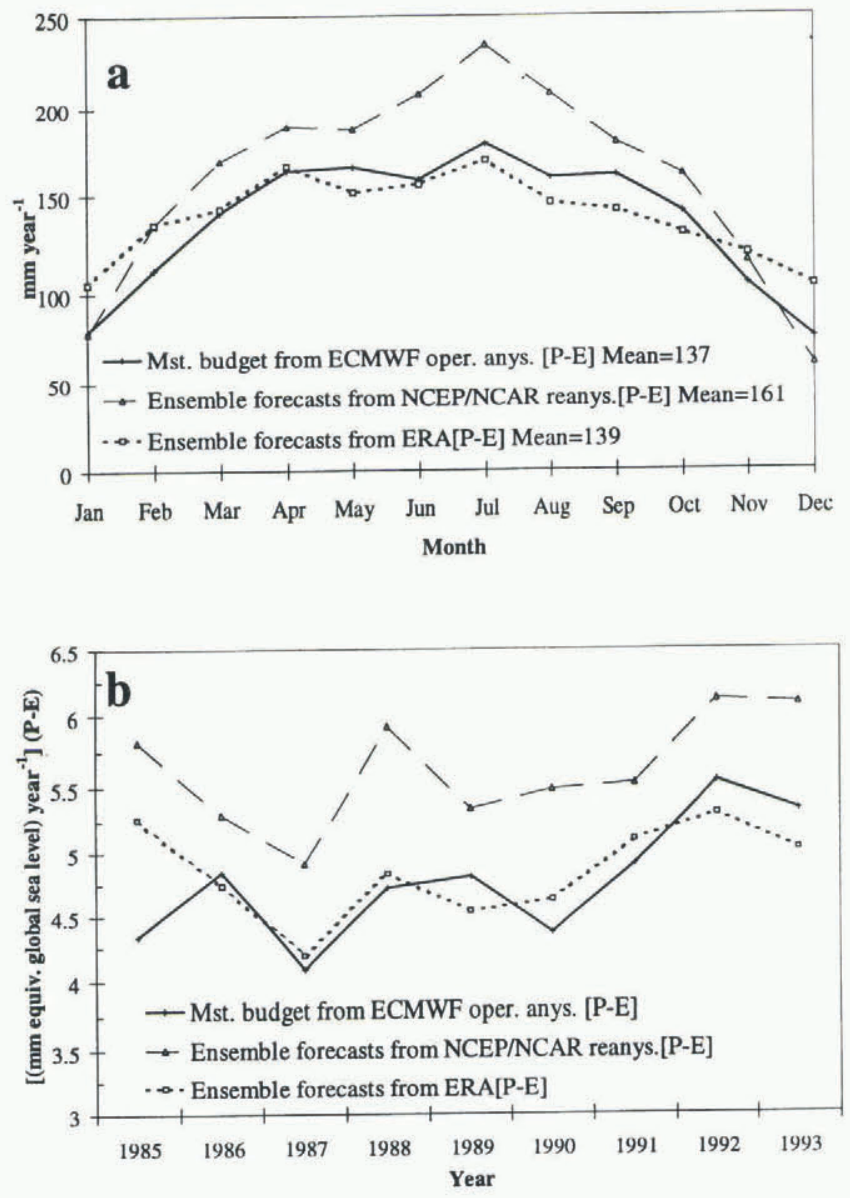

Fig. 4 (a) Comparison of average annual cycle from various climatologies for the region specified by available data in Figure 2a, averaged for the years 1985-93, in $\mathrm{mm} \mathrm{a}^{-1}$. (b) Comparison of annual average values for various climatologies, in units of $\mathrm{mm}$ ESL $a^{-1}$.

\section{DISGUSSION}

The comparison between glaciological data and time-averaged $P-E$ value shows general convergence on a value near $150 \mathrm{~mm} \mathrm{a}^{-1} \pm 13 \%$ for the continental average. This agreement gives confidence in validating global climate models using these long-term estimates. 
The decomposition of surface accumulation rates is of particular importance to atmospheric climate modeling, which prognoses precipitation and evaporation/sublimation rates separately. This is also essential to understanding accumulation fluctuations, as climate variability may impact the terms differently (Budd and Simmonds, 1991). Unfortunately this is the source of most of the disagreement among the methods examined here. The average NCEP/NCAR reanalysis values of $P$ and $E$ are 298 and $137 \mathrm{mma}^{-1}$, respectively, while the ERA values are 147 and $8 \mathrm{~mm} \mathrm{a}^{-1}$. The substantial difference in evaporation/sublimation, roughly a factor of 17 between the two re-analyses, has also been noted by Stendel and Arpe (1997). The annual cycles of evaporation/sublimation are also somewhat different. The very small number of regional observations suggests the annual cycle of evaporation/sublimation is characterized by very small or even negative (deposition) values for most of the year, with a marked increase in December and January (e.g. Loewe, 1962; Fujii and Kusunoki, 1982; Stearns and Weidner, 1993). Not shown, the curve for evaporation/sublimation over the annual cycle in the NCEP/NCAR reanalysis has roughly the same shape as these observations but with different values; relatively small values of $110 \mathrm{~mm} \mathrm{a}^{-1}$ occur from March to October, with much larger evaporation/sublimation rates of greater than $220 \mathrm{~mm} \mathrm{a}^{-1}$ in summer months. In contrast, the curve for evaporation/sublimation over Antarctica in the ERA more closely resembles a sine function, with small amounts of deposition occurring from June through September. The minimum average monthly evaporation/sublimation rate of $-1.8 \mathrm{~mm} \mathrm{a}^{-1}$ occurs in July, with a maximum rate of $28 \mathrm{~mm} \mathrm{a}^{-1}$ in December.

The amount of continental-averaged summer evaporation/sublimation is not presently known. Evaporation/sublimation had previously been thought to be negligible for large areas of the continental interior (e.g. Loewe, 1962), but recent observational studies from peripheral areas of the ice sheet (Fujii and Kusunoki, 1982; Faure and Buchanan, 1991; Stearns and Weidner, 1993) have found very large summer sublimation rates. These studies do not support either of the two evaporation/sublimation fields from the re-analysis products, however, since the NCEP/NCAR reanalysis evaporation/sublimation rates are more than twice as large as the substantial values reported by Stearns and Weidner (1993); the shape of the ERA evaporation/sublimation curve raises interesting questions about the ability of observational methods to measure deposition accurately. At present, there is considerable disagreement on the separated $P$ and $E$ terms for the Antarctic continent. This finding supports the use of the atmospheric moisture budget for determining $P-E$ collectively in atmospheric diagnostic studies.

\section{ACKNOWLEDGEMENTS}

The authors thank A. Ridout of the Climate Physics Group, University College London, for providing a reformatted version of the Giovinetto and Bentley (1985) digitized field. ECMWF data and the NCEP/NCAR re-analysis were obtained from NCAR. This research was sponsored by NASA under grants NAGW-3677 to the first author and W18795 to the third author. This is contribution No. 1061 of Byrd Polar Research Center.

\section{REFERENGES}

Bromwich, D. H. 1988. Snowfall in high southern latitudes. Rev. Geophys, 26(1), 149-168.

Bromwich, D. H. 1990. Estimates of Antarctic precipitation. Nature, $343(6259), 627-629$.

Bromwich, D. H. and F. M. Robasky. 1993. Recent precipitation trends over the polar ice sheets. Meteorol. Atmos. Phys., 51, $259-274$.

Bromwich, D. H., F. M. Robasky, R. I. Cullather and M. L. VanWoert. 1995. The atmospheric hydrologic cycle over the Southern Ocean and Antarctica from operational numerical analyses. Mon. Weather Rev., 123(12), 3518-3538.

Budd, W. F. and I. Simmonds. 1991. The impact of global warming on the Antarctic mass balance and global sea level. In Weller, G., C. L. Wilson and B. A. B. Severin, eds. International Conference on the Role of the Polar Regions in Global Change: proceedings of a conference held June 11-15, 1990 at the University of Alaska Fairbanks. Vol. II. Fairbanks, AK, University of Alaska. Geophysical Institute/Center for Global Change and Arctic System Research, $489-494$.

Budd, W. F., P. A. Reid and L. J. Minty. 1995. Antarctic moisture flux and net accumulation from global atmospheric analyses. Ann. Glaciol., 21, 149-156.

Connolley, W. M. and J. C. King. 1996. A modeling and observational study of East Antarctic surface mass balance. 7. Geophys. Res., 101(Dl), 1335 1344 .

Cullather, R. I., D. H. Bromwich and M. L. Van Woert. 1996. Interannual variations in Antarctic precipitation related to El-Niño-Southern Oscillation. J. Geophys. Res., 101 (D14), 19,109-19,118.

Cullather, R. I., D. H. Bromwich and R.W. Grumbine. 1997. Validation of operational numerical analyses in Antarctic latitudes. J. Geophys. Res., 102 (D12), 13,761-13,784.

Cullather, R. I., D. H. Bromwich and M. L. Van Woert. 1998. Spatial and temporal variability of Antarctic precipitation from atmospheric methods. 7. Climate, 11 (3), 334-368.

Faure, G. and D. Buchanan. 1991. Ablation rates of the ice fields in the vicinity of the Allan Hills, Victoria Land, Antarctica. In Elliot, D. H., ed. Contributions to Antarctic research II. Washington, DC, American Geophysical Union, 19-31. (Antarctic Research Series 53.)

Fortuin, J. P. F, and J. Oerlemans. 1990. Parameterization of the annual surface temperature and mass balance of Antarctica. Ann. Glaciol., 14, 78-84.

Frolich, R. M. 1992. The surface mass balance of the Antarctic Peninsula ice sheet. In Morris, E. M., ed. The contribution of Antarctic Peninsula ice to sea level rise. Cambridge, British Antarctic Survey, 3-9. (Ice and Climate Special Report 1.)

Fujii, Y. and K. Kusunoki. 1982. The role of sublimation and condensation in the formation of ice sheet surface at Mizuho Station, Antarctica. 7 . Geophys. Res., 87 (C6), 4293-4300.

Genthon, C. and A. Braun. 1995. ECMWF analyses and predictions of the surface climate of Greenland and Antarctica. J. Climate, 8(10), 2324-2332.

Gibson, R., A. Hernandez, P. Kålberg, A. Nomura, E. Serrano and S. Uppala. 1996. Current status of the ECMWF Re-Analysis (ERA) Project. In Seventh Symposium on Global Change Studies, 28 January - 2 February 1996, Atlanta, Georgia. Proceedings. Boston, MA, American Meteorological Society, 112-115.

Gibson, R., P. Kållberg, S. Uppala, A. Hernandez, A. Nomura and E. Serrano. 1997. ERA description. Reading, European Centre for Medium-Range Weather Forecasts. (ECMWF Re-Analysis Project Report Series 1.)

Giovinetto, M. B. and C. R. Bentley. 1985. Surface balance in ice drainage systems of Antarctica. Antarct. 7. U.S., 20 4), 6-13.

Higham, M. and M. Craven. 1997. Surface mass balance and snow surface properties from the Lambert Glacier basin traverses 1990-94. Hobart, Tasmania, Cooperative Research Centre for the Antarctic and Southern Ocean Environment. (Research Report 9.)

Howarth, D. A. 1986. An analysis of the water vapor flux divergence field over the Southern Hemisphere. Ann. Assoc. Am. Geogr., 76 (2), 190-207.

Jacobs, S. S., H. H. Hellmer, C. S. M. Doake, A. Jenkins and R. M. Frolich. 1992. Melting of ice shelves and the mass balance of Antarctica. F. Glaciol., 38 (130), 375-387.

Kalnay, E. and 21 others. 1996. The NCEP/NCR 40-year reanalysis project. Bull. Am. Meteorol. Soc., 77 (3), 437-471.

Loewe, F. 1962. On the mass economy of the interior of the Antarctic ice cap. J. Geophys. Res., 67 (13), 5171-5177.

Masuda, K. 1990. Atmospheric heat and water budgets of polar regions: analysis of FGGE data. Proc. NIPR Symp. Polar Meteorol. Glaciol. 3, 79-88.

Morgan, V. I., I. D. Goodwin, D. M. Etheridge and C.W. Wookey. 1991. Evidence from Antarctic ice cores for recent increases in snow accumulation. Nature, 354(6348), 58-60.

Mosley-Thompson, E. and 6 others. 1995. Recent increase in South Pole snow accumulation. Ann. Glaciol., 21, 131-138. 
Nerem, R. S. 1997. Global mean sea level change: correction. Science, 275 (5303), 1053.

Ohmura, A., M. Wild and L. Bengtsson. 1996. A possible change in mass balance of Greenland and Antarctic ice sheets in the coming century. 7. Climate, 9(9), 2124-2135.

Peixoto, J. P. and A. H. Oort. 1992. Physics of climate. New York, American Institute of Physics.

Serreze, M. C. and J. A. Maslanik. 1997. Arctic precipitation as represented in the NCEP/NCAR reanalysis. Ann. Glaciol., 25, 429-433.

Stearns, C. R. and G. A. Weidner. 1993. Sensible and latent heat flux estimates in Antarctica. In Bromwich, D. H. and C. R. Stearns, eds. Antarctic meteorology and climatology: studies based on automatic weather stations. Washington, DC, American Geophysical Union, 109-138. (Antarctic Research Series 61 .

Stendel, M. and K. Arpe. 1997. Evaluation of the hydrological cycle in reanalyses and observations. Hamburg, Max-Planck-Institut.

Thompson, S. L. and D. Pollard. 1997. Greenland and Antarctic mass balances for present and doubled atmospheric $\mathrm{CO}_{2}$ from the GENESIS version 2 global climate model. f. Climate, 10(5), 871-900.

Trenberth, K. E. 1992. Global analyses from ECMWFand atlas of 1000 and $10 \mathrm{mb}$ circulation statistics. Boulder, $\mathrm{CO}$, National Center for Atmospheric Research. (NCAR Technical Note TN-373+STR.)

Trenberth, K. E. and J. G. Olson. 1988. An evaluation and intercomparison of global analyses from NMC and ECMWF. Bull. Am. Meteorol. Soc., 69(9), 1047-1057.

Tzeng, R. -Y., D. H. Bromwich, T. R. Parish and B. Chen. 1994. NCAR CCM2 simulation of the modern Antarctic climate. 7. Geophys. Res., 99(Dl1), 23,131-23,148.

Warrick, R. A., C. le Provost, M. F. Meier, J. Oerlemans and P. L. Woodworth. 1996. Changes in sea level. In Houghton, J. T., L. G. M. Filho, B. A. Callander, N. Harris, A. Kattenberg and K. Maskell, eds. Climate change 1995: the science of climate change. Cambridge, etc., Cambridge University Press, 359-405.

Yamazaki, K. 1992. Moisture budget in the Antarctic atmosphere. Proc. NIPR Symp. Polar Meteorol. Glaciol. 6, 36-45.

Yamazaki, K. 1994. Moisture budget in the Antarctic atmosphere. International Association of Hydrological Sciences Publication 223 (Symposium at Yokohama 1993 - Snow and Ice Covers: Interactions with the Atmosphere and Ecosystems), 61-67. 